\section{Dealing with publication bias}

$\mathrm{T}$ There is a human trend to publish just clinical trials with positive results. This kind of systematic error or bias tends to mislead the readers. Faults of this nature are attributable to Editors' preferences for causing scientific impact with their publications, but evidence has also recently been put forward that the authors of clinical trials which did not detect the effect of new treatment tend not to submit the respective papers for publication'.

The result is that when publication bias occurs, there is the probability that the results of reviews will be incorrect. Because of this, the Cochrane Collaboration reviewers have taken on the commitment to search for all existing clinical trials regarding a specific therapeutics question, published or not. In other words, the value of a particular trial depends more on the methods included in its design and development, than on what journal it was published in.

In order to contribute to this subject, the São Paulo Medical Journal is joining the best international journals, like the Lancet, the British Medical Journal and the JAMA, in the Unpublished Trials Amnesty Campaign. Brazilian colleagues who have unpublished clinical trials may fill in and return the form included in this issue, or send the full paper to the São Paulo Medical Journal, so that they will have a chance of being included in a publication or at least in the Cochrane Database of Clinical Trials. Thus, they will gain the visibility to be included in systematic reviews and get citations and recognition. More details may be obtained in the next paper by Iain Roberts and Richard Smith, editor of the British Medical Journal.

"MD, PhD, MCE

Chaiman, Division of Internal Medicine, Escola

Paulista de Medicina, Editor São Paulo Medical Journal.

\section{"An amnesty for unpublished trials. Send us details on any unreported trials}

This month over 100 medical journals around the world are inviting readers to send information on unpublished trials. This amnesty should have important benefits for patients. Why?

Reports of properly conducted randomised controlled trials are the foundation of effective health care, but many are not submitted for publication ${ }^{1.2}$ This reduces the power of systematic reviews to detect moderate but clinically important treatment effects. Patients may thus be denied effective forms of health care. A second problem is that since trials that show more promising effects are more likely to be submitted, research syntheses can give misleading conclusions about effectiveness. Patients may thus be exposed to useless or even harmful treatments. ${ }^{3}$ Finally, patients may be asked to participate in new studies designed to address questions that have already been answered. ${ }^{4}$

Trials go unreported for a myriad of reasons: it is well documented that trials with non-significant results are substantially less likely to be submitted for publication.' Sometimes recruiting participants takes longer than expected at the expense of time set aside for report writing; investigators may change jobs and work remain unfinished; or investigators may discover a recently published trial on the same topic and conclude that their own results are redundant. Editors must also take some responsibility: there is a limit to the number of reports we can publish. Many investigators regret not having published their results, and when contacted almost all are delighted to provide them. 
Although amnesty means giving pardon, we hope that investigators will see this as an opportunity-namely, to make the results of previously unreported trials publicly accessible, thus having the potential to contribute to the scientific foundation of health care. We urge all investigators with unreported trial data to register their trials by returning a photocopy of the registration form shown below. We would like to register any unreported controlled trial, including trials that have only been published as an abstract.

Registration can be undertaken by anyone able to provide the registration information, even if they cannot provide the actual trial data. We expect a degree of duplicate registration. The information will be made available by listing the trial details on a web site and in other ways. If specific trial data are required, for example by those conducting systematic reviews, then the reviewer will be able to seek this information directly from the trialist. Some of the trials may be suitable for full publication, and the journal will be happy to consider these.

Medical editors are acutely aware of the trials and tribulations of research reporting. On this occasion, because of the serious implications of unreported research, we are trying to cleave the trials from the tribulations. We are confident of a good response."

Richard Smith - Editor, BMJ

Ian Roberts - Director

Child Health Monitoring Unit, Institute of Child

Health, London WC1N 1EH

\section{REFERENCES}

1. Dickersin K, Min YI. NIH clinical trials and publication bias. On-line J Curr Clin Trials [serial online] 1993; 28 Apr: Doc No 50.

2. Easterbrook PJ, Berlin JA, Gopalan R, Matthews DR. Publication bias in clinical research. Lancet 1991;337:867-72.

3. Egger M, Davey Smith G. Misleading meta-analysis. BMJ 1995;310:752-4.

4. Savulescu J, Chalmers I, Blunt J. Are research ethics committees behaving unethically? Some suggestions for improving performance and accountability. BMJ 1996;313:1390-3.

\section{Unreported trial registration form}

Register any controlled trial which has not been published in full, including trials that have been published only as an abstract. Registration can be undertaken by anyone able to provide registration information, even if they are unable to provide the actual trial data. Please complete one form for each trial being registered.

\section{Contact details}

Surname:

Postal address:

\section{Trial details}

Approximate number of participants in the trial:

Type of participants (eg people with head injury, women at risk of breast cancer):

Type of intervention (eg steroids versus placebo, annual mammography versus standard practice: versus

Please post or fax registration forms to: Medical Editors' Trial Amnesty, BMJ Editorial Department, Tavistock Square, London WC1H 9JR. Fax: 44 (0) 171383 6418. Alternatively the information can be sent by email to: meta@ucl.ac.uk 